\title{
Women's denial of having experienced female genital cutting in northern Ghana: Explanatory factors and consequences for analysis of survey data
}

Elizabeth F. Jackson

Population Council

Patricia Akweongo

Evelyn Sakeah

Abraham Hodgson

Rofina Asuru

See next page for additional authors

Follow this and additional works at: https://knowledgecommons.popcouncil.org/departments_sbsr-pgy

Part of the Demography, Population, and Ecology Commons, Family, Life Course, and Society

Commons, International Public Health Commons, and the Sociology of Culture Commons

How does access to this work benefit you? Let us know!

\section{Recommended Citation}

Jackson, Elizabeth F., Patricia Akweongo, Evelyn Sakeah, Abraham Hodgson, Rofina Asuru, and James F. Phillips. 2003. "Women's denial of having experienced female genital cutting in northern Ghana: Explanatory factors and consequences for analysis of survey data," Policy Research Division Working Paper no. 178. New York: Population Council. 
Authors

Elizabeth F. Jackson, Patricia Akweongo, Evelyn Sakeah, Abraham Hodgson, Rofina Asuru, and James F. Phillips 


\section{Women's D enial of H aving} Experienced Female Genital Cutting in Northern Ghana: Explanatory Factors and Consequences for Analysis of

\section{Survey D ata}

Elizabeth F. Jackson

Patricia Akweongo

Evelyn Sakeah

Abraham Hodgson

Rofina Asuru

James F. Phillips

$>$

2003 No. 178 


\title{
Women's Denial of Having Experienced Female Genital Cutting in Northern Ghana: Explanatory Factors and Consequences for Analysis of Survey Data
}

\author{
Elizabeth F. Jackson \\ Patricia Akweongo \\ Evelyn Sakeah \\ Abraham Hodgson \\ Rofina Asuru \\ James F. Phillips
}

Elizabeth F. Jackson is Staff Associate at the Population Council. Patricia Akweongo is Research Officer, Evelyn Sakeah is Research Assistant, and Abraham Hodgson is Director of the Navrongo Health Research Centre in northern Ghana. Rofina Asuru is Principal Investigator of the Navrongo Community Health and Family Planning Experiment at the Navrongo Health Research Centre. James F. Phillips is Senior Associate at the Population Council. This research was made possible by the generous support of USAID Cooperative Agreement No. HRN-A-00-99-00010. 


\begin{abstract}
Although many cross-sectional social surveys have included questions about female genital cutting status and correlated personal characteristics, no longitudinal studies have been launched that permit investigation of response biases associated with such surveys. This paper reports on a longitudinal study of women aged 15 to 49 in rural northern Ghana. The self-reported circumcision status of women interviewed in 1995 was compared with the status they reported when they were interviewed again in 2000 after the government began enforcing a law banning the practice and public information campaigns against it were launched. In all, 13 percent of respondents who reported in 1995 that they had been circumcised denied that they were circumcised in the 2000 reinterview, although denial rates were as high as 50 percent in the youngest age group. Analysis shows that women who denied being circumcised are significantly younger, more likely to be educated, and less likely to practice traditional religion than are women who reported that they were circumcised. Factors that may explain these correlates of denial are discussed, and implications for research are reviewed.
\end{abstract}

This material may not be reproduced without written permission from the authors. For a list of Policy Research Division Working Papers, including those available for downloading in PDF format, see www.popcouncil.org/publications/wp/prd/rdwplist.html. 
Female genital cutting, also known as female circumcision or female genital mutilation, has received growing attention from governmental and international organizations during the past decade. It is commonly considered a human rights violation, and international pressure has been exerted on governments, communities, and individuals to eliminate the practice (Shell-Duncan and Hernlund 2000). At the same time that a variety of strategies to discourage the practice have been implemented, researchers have called for increased rigor in documenting the specific health effects of genital cutting and the impact of intervention programs to end it (Obermeyer 1999). Interest in research to document the prevalence, determinants, and health effects of genital cutting, as well as in development of appropriate intervention strategies with proved effectiveness, is growing rapidly (Population Council 2002; Sedgh and Jackson 2003).

Accurate measurement of the circumcision status of individuals is crucial to the success of the research agenda. Accurate assessment of individuals' status is necessary for evaluation of interventions, for studies of the determinants of the practice, and for investigations of prevalence trends given in national surveys. In the last five years, the number of reliable national surveys of prevalence has grown substantially. By 2001, the Demographic and Health Surveys had collected data in 12 countries in Africa. ${ }^{1}$

Although many surveys have included questions about women's circumcision status and correlated personal characteristics, we are aware of no longitudinal studies that permit research on survey-response biases. Investigation of the possibility of response bias assumes growing importance as the legislation and informational campaigns against the practice increase, possibly affecting survey-response validity. ${ }^{2}$ This paper examines the determinants of inconsistent self-reporting of circumcision status by comparing women's self-reported status from survey responses in 1995 with repeat-interview responses in 2000 for a sample population living in a rural area of northern Ghana, where the practice of female genital cutting has been the subject of legislation and informational campaigns.

\section{BACKGROUND}

Although medical examination represents the gold standard for assessing whether or not a girl or woman has been circumcised, this method has several drawbacks. Medi- 
cal examinations are costly and, by necessity, are almost always performed on selfselected subgroups of a population such as clinic clientele. Validation studies using random population-based samples are rare and difficult to implement. ${ }^{3}$ More commonly, women are examined in the context of clinic attendance. Examples of this type of study include research undertaken in 1996 in Egypt based on a sample of 1,339 women attending gynecological and family planning clinics (Huntington et al. 1996) and a clinicbased study of the health effects of female circumcision in Burkina Faso and Mali (Jones et al. 1999).

Other methods of assessing individuals' circumcision status include self- or parental reporting, methods that are typically used in sociodemographic surveys. The accuracy of these methods can be compromised in two ways: First, women may not know whether they have been circumcised, and parents' knowledge of a daughter's status may be inaccurate. Second, respondents or parental informants may deliberately mislead survey interviewers about the issue.

Even in settings where genital cutting can occur at an early age, the accuracy of women's knowledge about their own status is generally high, as gauged by comparison of women's self-reports with subsequent clinical examinations. The 1996 Egyptian study mentioned above found 92 percent agreement between self-reported circumcision status and gynecological assessment. In gynecological exams, a prevalence of female genital cutting of 93 percent was recorded, whereas women's self-reports indicated a prevalence of 97 percent (Huntington et al. 1996). Additional calculations performed on estimates from data published in the study indicate that approximately 1 percent of women clinically confirmed to be circumcised reported that they were not. Inaccurate reporting was more prevalent, however, among women who were clinically confirmed to be uncircumcised: Approximately 71 percent of these women erroneously reported that they had been circumcised. ${ }^{4}$ In a 1999 study in rural Gambia, the self-reported circumcision status of 1,156 women agreed with assessments made by a gynecologist in 97 percent of cases (Morison et al. 2001). The study found a prevalence of 58 percent both among women examined and among women surveyed. Additional calculations performed on these data indicate that 1 percent of women identified as circumcised in their examination reported that they had not been circumcised, 1.5 percent of women identified as 
circumcised in their examinations reported a type of circumcision different from that recorded during their exam, and 4.7 percent of women who had not been circumcised reported that they had been. ${ }^{5}$

Two recently published studies conducted in southwest Nigeria looked at the accuracy of self-reports of female circumcision status in settings where prevalence of the practice was determined to be 45 and 46 percent (Larsen and Okonofua 2002; Snow et al. 2002). Larsen and Okonofua found a high level of agreement, 92 percent, between exams and self-reports, although 17 percent of women did not respond or responded that they did not know whether they were circumcised. Their study recorded a prevalence of female genital cutting of 45 percent among medically examined women. Nine percent of women who were found to be uncircumcised in an exam said that they were circumcised, and 6 percent of women found to be circumcised in an exam said that they had not been. ${ }^{6}$ Snow et al. documented a lower level of agreement ( 79 percent) between gynecological exams and self-reports and a substantial proportion of women who reported that they did not know their status (14 percent). ${ }^{7}$ Their clinical study recorded a prevalence of circumcision of 46 percent.

Because participants had consented to a gynecological examination prior to being interviewed, disagreement between self-reports and examination results likely represents either women's inaccurate knowledge or incorrect examination assessments rather than women's conscious choice to misrepresent their status to interviewers. Women in each of these studies would have been less likely to misreport their circumcision status willfully since they knew that it would be revealed in the subsequent gynecological examination. In each study, inaccurate reporting of status is more prevalent among women who are classified as uncircumcised during an examination compared with women classified as circumcised. The highest prevalence of inaccurate reporting is found among uncircumcised women in Egypt, where the prevalence of the practice is highest. This high rate of inaccurate reporting may be the result of the growing incidence in Egypt of medicalized cutting procedures that are difficult to detect in a physical examination (El-Gibaly et al. 2002). Moreover, uncircumcised respondents may consider their status to be socially unacceptable in a country like Egypt where the practice is highly prevalent. 
No study has compared self-reported circumcision status among women who had consented to a physical examination with responses of women who did not know that they would be asked to undergo an examination. This paper examines inconsistencies between self-reports of circumcision status in successive interviews. Analyses are based on the assumption that longitudinal data on circumcision status provide analytical resources for examining the validity of such self-reported data. Although in the present longitudinal survey no physical examination is available to determine a woman's true status, a reversal of status from circumcised to uncircumcised is an obvious impossibility, and a response that suggests such a reversal may indicate a woman's decision to give a false answer. As noted above, inconsistencies are examined here by means of a comparison of women's self-reported status in two linked panel surveys from 1995 and 2000 in a rural area of northern Ghana. The survey responses of women who claimed to be circumcised when they were interviewed in 1995 were examined for consistency and response reversal when they were reinterviewed in 2000.

\section{SETTING}

Our study is a component of an experimental investigation launched by the Navrongo Health Research Centre (NHRC) in Kassena-Nankana District in northeastern Ghana at the border of Burkina Faso. Two ethnolinguistically distinct groups populate the district, the Kassena and the Nankana. Although their languages differ, the Kassena and Nankana share similar traditional patriarchal social institutions and economies based on subsistence agriculture. The district reflects ecological conditions characteristic of the vast Sahelian hinterland of Burkina Faso, Mali, and Niger, as well as the northern regions of Côte d'Ivoire, Ghana, and Togo where the climate is semiarid Guinea savanna with one rainy season from June through October. The productivity of Sahelian subsistence farming is increasingly constrained by erosion, soil depletion, and decreasing rainfall. The district is located in the Upper East Region, which is the poorest in Ghana.

The NHRC is a public-health research center of the Ghana Health Service with ongoing protocols for a variety of health-related studies. The core scientific resource of the NHRC is the Navrongo Demographic Surveillance System (NDSS), a longitudinal population monitoring system that has registered individuals present in the district, de- 
mographic events, population characteristics, and social relationships since the system was launched in 1993. Yearly panel surveys collect more detailed information on a population subset of women aged 15 to 49 and their husbands resident in 18 percent of the 12,700 extended family compounds registered in the NDSS. In 1995, a questionnaire module assessed self-reported female circumcision status. Findings showed that 77 percent of the respondents reported that they had undergone genital cutting, a clear indication that the practice persists in the district. A research program using both qualitative and quantitative methods to assess trends in the practice was begun immediately. Efforts have culminated in a five-year study, begun in 1999, to develop, test, and implement an intervention to hasten the demise of genital cutting.

Female genital cutting has been a fundamental feature of the transition to adulthood for Kassena and Nankana adolescent girls at least since the early 1900s (Rattray 1932; Adongo et al. 1998; Mensch et al. 1998; Akweongo et al. 2001). Although female circumcision is believed to have been widely practiced in the district for several generations, when the practice began is not known. It was likely a result of the influence of peoples to the north in Burkina Faso and Mali with whom the Kassena and Nankana share ethnolinguistic ties.

The practice appears to be undergoing major change in the district. In a 1995 panel survey of women aged 15 to 49, 94 percent of women aged 35 years and older reported that they had been circumcised. The prevalence of circumcision steadily decreased according to respondents' age. Among the youngest age group interviewed, those 15 to 19 years old, only 26 percent reported that they had been circumcised (Mbacké et al. 1998). The 2000 panel survey showed that the prevalence of circumcision among women aged 35 years and older had decreased to 83 percent, whereas prevalence had reached a low of 8 percent among women aged 15 to 19 . Our analysis, based on the 2000 survey, of women's denial of having experienced female genital cutting partially explains the decrease in reported prevalence of the practice.

\section{METHODOLOGY}

This study examines the consistency of self-reported genital cutting status among women aged 15 to 49 who were interviewed in panel surveys in 1995 and in 2000. In 
both surveys, women were asked about their background characteristics including ethnicity, religion, education, and marital status. Other topics routinely covered included reproductive history, fertility preferences, and contraceptive knowledge and use. In 1995, 5,275 women were asked about their status with the question, "Are you circumcised?" In 2000, 6,136 women were asked the same question. When the two surveys were linked, 2,401 women were found to have been interviewed in both years, and 2,391 of these women answered the question about circumcision status in both years. ${ }^{8}$

These linked responses were analyzed for consistency and placed into four categories. In the first two categories, agreement occurred when a woman consistently reported either being circumcised or uncircumcised in both of her survey responses. Women who reported consistently that they are circumcised are referred here to as "confirmers." Women who reported consistently that they have not been circumcised are referred to here as "uncircumcised." In the third and fourth categories, disagreement occurred when a woman's responses were inconsistent, either because she stated that she was not circumcised in 1995 and reported that she was circumcised in 2000, indicating the probable occurrence of a procedure during the study period, or because a woman who reported that she was circumcised in 1995 reported that she was not circumcised in 2000 , indicating probable denial. We assume that women who reported they were not circumcised in 1995 and who reported they were circumcised in 2000 are newly circumcised, and we label this pattern as "newly circumcised." Women who reported in 1995 that they were circumcised and reported in 2000 that they were not are identified here as "deniers." The denial rate is calculated as the proportion of the number of women who reported that they were circumcised in 1995 who reported in 2000 that they were not.

Our analysis consists of a tabulated comparison of the characteristics of women who fall into each of the four types of response pairs and a series of logistic regression models that show the relationship between background characteristics and response consistency and accuracy. The characteristics expected to influence a woman's genital cutting status and her reporting of that status include her age, education, religion, ethnicity, marital status (whether unmarried, monogamous, or polygamous), use of contraceptives, and employment. 
A high rate of response reversal representing possible denial of having been circumcised was expected because of the growing influence of a law passed by the government of Ghana in 1994 banning the practice and of public information campaigns that were launched to uproot social support for it.

\section{RESULTS}

Comparison of prevalence rates among cohorts shows a dramatic decline in the practice of female circumcision during the 1995-2000 period. Table 1 shows that the decline in the reported prevalence of genital cutting is greatest among younger cohorts. The self-reported prevalence of the practice declined among older women as well, however. Because the two surveys occurred five years apart, most of the women interviewed in 1995 are five years older in 2000, depending on the exact timing of the surveys. When the prevalence of circumcision among women aged 35 to 39 in 1995 is compared with prevalence among the same cohort, aged 40 to 44, in 2000, it is found to have dropped from 92 percent to 84 percent. A similar decrease in self-reported prevalence occurs among all age cohorts. Such a drop would only be expected if a large number of uncircumcised adult women moved into the area or if women who reported that they were circumcised in 1995 reported that they were not in 2000.

Table 1 Percentage of women interviewed in Kassena-Nankana District who reported in cross-sectional surveys that they had been circumcised, by age group, Ghana, 1995 and 2000

\begin{tabular}{lcc}
\hline Age group & $\mathbf{1 9 9 5}$ & $\mathbf{2 0 0 0}$ \\
\hline $15-19$ & 26 & 8 \\
$20-24$ & 58 & 25 \\
$25-29$ & 82 & 49 \\
$30-34$ & 89 & 70 \\
$35-39$ & 92 & 78 \\
$40-44$ & 95 & 84 \\
$45-49$ & 96 & 87 \\
Total & 77 & 52 \\
(No. interviewed) & $(5,275)$ & $(6,136)$ \\
\hline
\end{tabular}


Linking data from the 1995 and 2000 surveys permits a comparison of individual self-reported responses concerning circumcision status among 2,391 women who reported their status in both years. This linked sample was classified into respondents who reported in both surveys that they were circumcised, those who reported in both surveys that they had not been circumcised, those who first reported in 2000 that they were circumcised, and those who reported in 1995 that they were circumcised but in 2000 said that they were not (as shown in Table 2).

As noted above, individual-level data reveal that denial of circumcised status is most prevalent among younger women. Nearly 16 percent of respondents in their twenties in 2000 denied having been circumcised, whereas only 8 percent of respondents in their forties did so. Prevalence of newly circumcised cases decreased steadily by age, and the number of respondents confirming their circumcised status increased steadily with age from 15 percent to 87 percent.

Examining cross-sectional prevalence by age group reveals a decrease in the prevalence of female genital cutting that may in part indicate denial. Confirming the accuracy of women's denial necessitates individual physical examinations, however. The rate of denial in 2000 among 2,000 women who reported in 1995 that they were circumcised is presented in Table 3. Of the 48 women aged 20 to 24 in 2000 who reported that they were circumcised in 1995, 50 percent reported in 2000 that they were not circumcised. Rates shown in Table 3 confirm that the denial rate decreases with age: Only 7 percent

Table 2 Percentage of 2,391 women interviewed in 1995 and 2000 panel surveys reporting one of four circumcision categories, by age group in 2000, KassenaNankana District, Ghana

\begin{tabular}{lcccc}
\hline Age in 2000 & Confirmers & Uncircumcised & Newly circumcised & Deniers \\
\hline $20-24$ & 15 & 61 & 8 & 15 \\
$25-29$ & 50 & 27 & 6 & 16 \\
$30-34$ & 71 & 12 & 5 & 12 \\
$35-39$ & 79 & 5 & 4 & 12 \\
$40-44$ & 85 & 4 & 3 & 8 \\
$45-49$ & 87 & 4 & 2 & 7 \\
Total & 73 & 12 & 4 & 11 \\
(No. reporting status) & $(1,746)$ & $(291)$ & $(100)$ & $(254)$ \\
\hline
\end{tabular}


Table 3 Percentage of 2,000 women aged 20-49 who denied that they were circumcised in 2000 and had previously reported in 1995 that they were circumcised, by age group, Kassena-Nankana District, Ghana

\begin{tabular}{lc}
\hline Age in 2000 & Percent denying in 2000 \\
\hline $20-24$ & 50 \\
$25-29$ & 24 \\
$30-34$ & 14 \\
$35-39$ & 13 \\
$40-44$ & 8 \\
$45-49$ & 7 \\
Total & 13 \\
\hline
\end{tabular}

of women in the 45-49 age group who had previously reported being circumcised subsequently reported that they were not. Denial rates are highest among groups of women with lowest prevalence.

Binomial and multinomial logistic regression models were estimated to examine the determinants of denial. Multinomial analysis was used to assess the odds of denial, the odds of new cases of circumcision, and the odds of reporting being uncircumcised in both surveys relative to the odds of reporting being circumcised in both surveys. The same regression model was estimated with a different reference category in order to examine the similarities between deniers, those who reported for the first time in 2000 that they had been circumcised, and women who reported in both surveys that they had been circumcised, relative to women who, in both surveys, reported that they had not.

Results of the estimation of the model using confirmers as the comparison category are presented in the three left-hand columns of Table 4 . Women who first reported in 2000 that they had been circumcised were more highly educated and more likely to report having ever used a family planning method compared with women who reported in both surveys that they were circumcised. These newly circumcised women did not differ from previously circumcised women in their religious identification or ethnicity.

Women who denied that they were circumcised in 2000 and women who in both years reported being uncircumcised shared many similarities relative to confirmers. Deniers and uncircumcised women were significantly younger, more likely to be educated, 
Table 4 Odds ratios from a multinomial logistic regression model of reported circumcision status in 2000 among 2,449 Ghanaian women interviewed in 1995 and 2000 , by selected variables

\begin{tabular}{|c|c|c|c|c|c|c|}
\hline \multirow[b]{2}{*}{ Variables } & \multicolumn{3}{|c|}{$\begin{array}{l}\text { Relative to women who } \\
\text { reported being circumcised } \\
\text { in both years (confirmers) }\end{array}$} & \multicolumn{3}{|c|}{$\begin{array}{l}\text { Relative to women who } \\
\text { reported being uncircumcised } \\
\text { in both years }\end{array}$} \\
\hline & Deniers & $\begin{array}{c}\text { Newly } \\
\text { circumcised }\end{array}$ & $\begin{array}{c}\text { Uncir- } \\
\text { cumcised }\end{array}$ & Deniers & $\begin{array}{c}\text { Newly } \\
\text { circumcised }\end{array}$ & $\begin{array}{c}\text { Con- } \\
\text { firmers }\end{array}$ \\
\hline$\overline{\text { Age }}$ & $0.746^{* *}$ & 0.768 & $0.585^{* * *}$ & $1.275^{*}$ & 1.312 & $1.709^{* * * *}$ \\
\hline Age squared & $1.003^{*}$ & 1.002 & $1.006^{* * *}$ & 0.997 & 0.997 & $0.994^{* * *}$ \\
\hline \multicolumn{7}{|l|}{ Education } \\
\hline None (r) & 1.000 & 1.000 & 1.000 & 1.000 & 1.000 & 1.000 \\
\hline Primary & $1.421^{*}$ & 0.993 & $2.101^{* * *}$ & 0.676 & $0.472^{*}$ & $0.476^{* * *}$ \\
\hline Middle + & $3.233^{* * *}$ & $2.524^{* *}$ & $10.270^{* * *}$ & $0.315^{* * *}$ & $0.246^{* * *}$ & $0.097^{* * *}$ \\
\hline Traditional religion & $0.749^{*}$ & 0.725 & $0.469^{* * *}$ & $1.598^{*}$ & 1.546 & $2.133^{* * *}$ \\
\hline \multicolumn{7}{|l|}{ Ethnicity } \\
\hline Kassena (r) & 1.000 & 1.000 & 1.000 & 1.000 & 1.000 & 1.000 \\
\hline Nankana & $1.731^{* * *}$ & 1.066 & 1.329 & 1.302 & 0.802 & 0.752 \\
\hline Bulsa or other & $2.395^{* *}$ & 1.081 & $2.049^{*}$ & 1.169 & 0.527 & $0.488^{*}$ \\
\hline \multicolumn{7}{|l|}{ Marital status } \\
\hline Unmarried (r) & 1.000 & 1.000 & 1.000 & 1.000 & 1.000 & 1.000 \\
\hline Polygamous & 1.048 & 0.708 & $0.433^{* * *}$ & $2.419^{* *}$ & 1.635 & $2.308^{* * *}$ \\
\hline Monogamous & 1.382 & 0.853 & 0.748 & $1.847^{*}$ & 1.140 & 1.336 \\
\hline Reported contraceptive use & 0.929 & $1.501^{*}$ & $1.418^{*}$ & $0.655^{*}$ & 1.058 & $0.705^{*}$ \\
\hline Employed & 1.075 & 0.659 & 0.720 & 1.494 & 0.915 & 1.389 \\
\hline $\begin{array}{l}\text { Log-likelihood } \\
\text { Likelihood-ratio chi-square }\end{array}$ & \multicolumn{3}{|c|}{-1683.8737} & \multicolumn{3}{|c|}{-1683.8737} \\
\hline $\begin{array}{l}\text { Likelihood-ratio chi-square } \\
\text { (33 degrees of freedom) }\end{array}$ & \multicolumn{3}{|c|}{$729.72(\mathrm{p}<0.0000)$} & \multicolumn{3}{|c|}{$729.72(\mathrm{p}<0.0000)$} \\
\hline Pseudo R squared & \multicolumn{3}{|c|}{0.1781} & \multicolumn{3}{|c|}{0.1781} \\
\hline
\end{tabular}

${ }^{*}$ Significant at $\mathrm{p}<0.05 ;{ }^{* *} \mathrm{p}<0.01 ;{ }^{* * *} \mathrm{p}<0.001 .(\mathrm{r})=$ Reference category.

more highly educated, and less likely to practice traditional religion. They were also more likely to be of Bulsa ethnicity relative to confirmers. Deniers were also more likely than confirmers to be of Nankam ethnicity. In other words, women who consistently reported being circumcised were more likely to be Kassim, while women who denied being circumcised were less likely to be Kassim. ${ }^{9}$

Women who in both surveys reported being uncircumcised had the highest educational levels of all women, with a tenfold odds of having attended school at the middle or higher level relative to confirmers. They were also less than half as likely as confirmers 
to practice traditional religion and less than half as likely to be in polygamous marriages. Moreover, they had a 1.4-fold odds ratio of reporting ever having practiced family planning relative to confirmers.

Odds ratios from the same model with women who in both years reported being uncircumcised as the comparison category are presented in the three right-hand columns of Table 4. Both deniers and confirmers are significantly older than women who reported being uncircumcised, although deniers, as we know from the first estimation of the model, tend to be younger than confirmers. Both deniers and confirmers are less likely to be educated at the middle school or higher level than are women who reported being uncircumcised. Both are more likely to practice traditional religion, more likely to be in polygamous unions, and less likely to have reported ever using a family planning method than are women who in both years reported being uncircumcised.

The main difference between deniers and confirmers relative to women who reported being uncircumcised is that deniers are significantly more likely to be married, whether in monogamous or polygamous unions. Confirmers, on the other hand, are more likely to be in polygamous unions than are women who reported been uncircumcised, but are equally likely to be in a monogamous union.

Deniers appear to occupy a middle ground between confirmers and women who reported that they have not been circumcised. Although deniers are more likely to be educated than confirmers, they are less likely to be highly educated than are women who reported being uncircumcised. Deniers are less likely than confirmers to practice traditional religion but more likely than women who reported in both surveys that they are uncircumcised to practice traditional religion. Below we present hypotheses about why the characteristics of deniers place them in this middle ground.

Our analysis investigates the possible bias introduced by denial of circumcision with regard to conclusions about the prevalence and determinants of circumcision. This exercise is performed in order to estimate the extent of the bias caused by denial in a hypothetical cross-sectional study of prevalence. When deniers are treated as uncircumcised, as they would be if we examined data from the 2000 survey without knowledge of the responses women gave in the 1995 survey, we would conclude that the prevalence of female genital cutting among women aged 20-49 was 77 percent overall. Knowledge of 
prior responses shows that if we counted deniers as circumcised, prevalence would jump to 88 percent. ${ }^{10}$ As expected, denial caused a substantial decrease in the measured prevalence of female circumcision.

To examine the bias caused by denial in conclusions about the determinants of circumcision, we constructed three logistic regression models in which deniers were treated in analysis first as circumcised, second as uncircumcised, and third as excluded. This approach was used to facilitate comparison of the odds ratios assigned to covariates when the responses of women who deny are "corrected" and treated as indicators of circumcision, when responses of women who deny are treated as indicators of uncircumcised status, and when responses of women who deny are excluded from the analysis. The results of this exercise are presented in Figure 1.

Figure 1 Odds ratios that circumcised women display selected background characteristics compared with uncircumcised women, from three maximum-likelihood logistic regression models with different classification of "deniers," among women aged 20-49, Kassena-Nankana District, Ghana, 2000

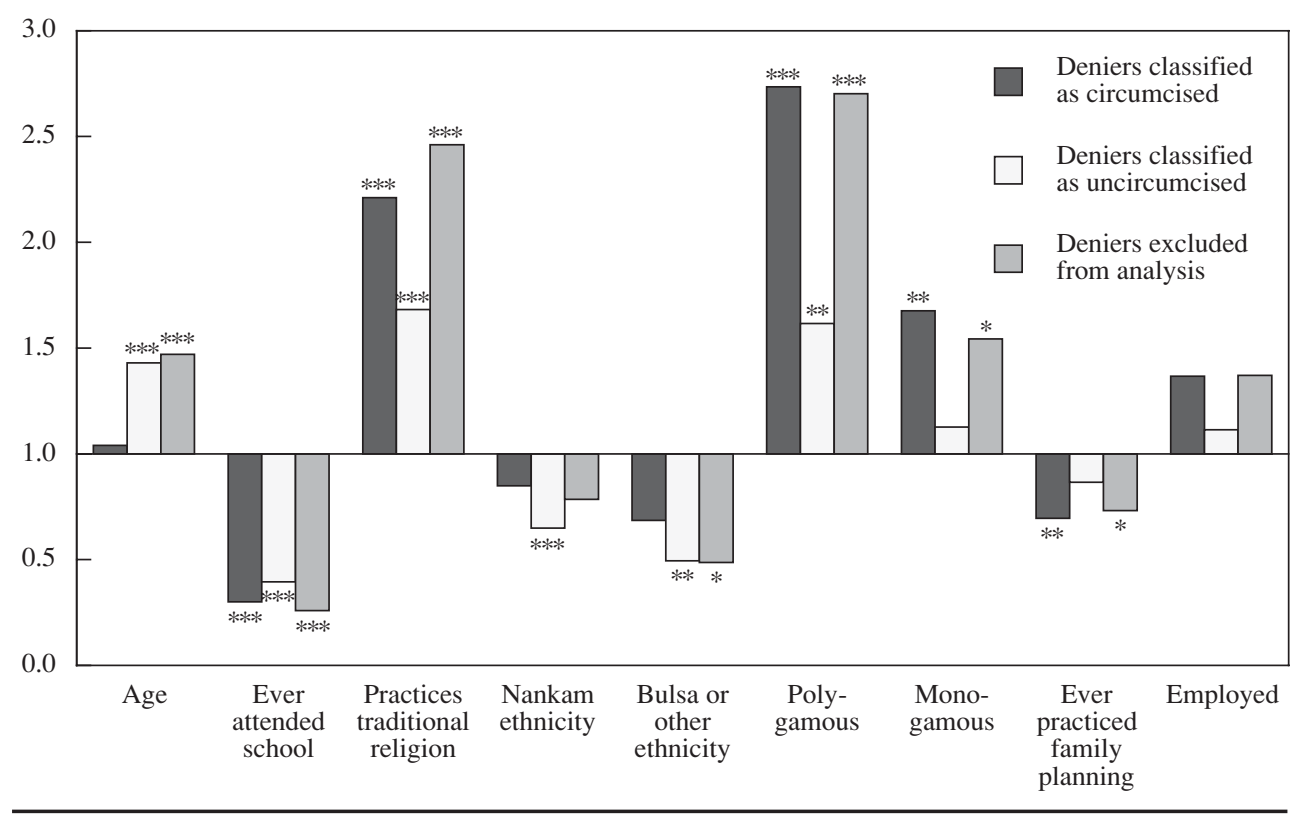

* Significant at $\mathrm{p}<0.05 ;{ }^{* *} \mathrm{p}<0.01 ;{ }^{* * *} \mathrm{p}<0.001$. 
Comparison of the covariates used in each model demonstrates that the classification of deniers as either circumcised or uncircumcised leads to different conclusions about the relationship between circumcision status and education, religion, age, ethnicity, and contraceptive use. When deniers are treated as circumcised, they are less than onethird as likely to have ever attended school compared with uncircumcised women. Circumcised women are more than two times more likely to practice traditional religion than are uncircumcised women and are significantly less likely than uncircumcised women to have ever used a family planning method. The model shows that no significant difference exists in age, ethnicity, or employment between circumcised and uncircumcised women.

When deniers are treated as uncircumcised, as they would be if we looked at the 2000 survey on its own, we reach different conclusions about the relationship between a woman's circumcision status and her individual characteristics. For example, the relationships between circumcision status and Nankam, Bulsa, or other ethnicity become significant and negative, and those between circumcision status and age become significant and positive. Relationships between circumcision status and education and religion remain significant and in the same direction although not as strong. The significant relationship observed between contraceptive-method use and circumcision status disappears when deniers are treated as uncircumcised women.

A final difference between the two models in which deniers are not excluded is that the relationship between marital status and circumcision is not as strong when deniers are classified as uncircumcised. In that case, circumcised women have 1.6-fold odds of being in a polygamous marriage relative to uncircumcised women, and no relationship is found between monogamy and circumcision status. When deniers are treated as circumcised, circumcised women are nearly three times more likely to be in a polygamous union compared with uncircumcised women and 1.7 times more likely to be in a monogamous marriage.

In each of the models based on the three possible ways of classifying deniers, we conclude that circumcised women are older than uncircumcised women, although this relationship is not significant when deniers are counted as circumcised. No significant relationship exists between circumcision status and employment. 
Because women's self-report is used to assess circumcision status in numerous surveys, including those administered by the Demographic and Health Surveys, the possibility exists that denial influences conclusions drawn about the determinants of female genital cutting. The present analysis demonstrates that bias introduced by denial leads to incorrect estimations of the relationship between circumcision and several key background characteristics. In this case, denial produces underestimates of the magnitude of the relationship between genital cutting and marital status, traditional religion, and education, and it leads to completely different conclusions about the significance of the relationship between circumcision status and age, ethnicity, and contraceptive use.

\section{DISCUSSION}

The interpretations of women's denial of being circumcised and of their being newly circumcised are dependent on which of the two self-report responses we choose to consider as accurate. When we classify women who initially reported that they are not circumcised and subsequently reported that they are newly circumcised, we must consider the possibility that some of these new cases are prior deniers who have, for some reason, decided to reveal their true circumcised status. The women classified as newly circumcised are younger, increasing the likelihood that they represent actual new cases of circumcision rather than previous deniers who have decided to report their status accurately. ${ }^{11}$

To interpret correctly the circumcision status of those women who first reported that they are circumcised and later reported that they are not, we must assess the accuracy of their responses. In some cases, women may have chosen to report that they are not circumcised when they are. In other cases, uncircumcised women may have reported previously that they were circumcised, perhaps because they felt pressured to give what they thought was a socially acceptable response. When these women subsequently (and accurately) reported their status as uncircumcised, we risk falsely classifying them as deniers.

For a variety of reasons outlined below, we believe that the women whom we have classified as deniers are likely to be reporting their status inaccurately. The spreading awareness of the law banning female genital cutting in Ghana that was introduced in 
1994 may have influenced circumcised women to conceal their status. The effects of this law were not likely to have been widespread at the time of the 1995 panel survey; however, most women were probably aware of the law after 1996, when a circumciser in the district was jailed for five years.

The effect of the law on survey responses may differ by age. Younger women may be more likely than older women to fear punishment under the law if they report being circumcised, because they have been more recently circumcised, and therefore their circumciser is still likely to reside in the community. Older women, almost universally circumcised, might fear the law less because they were circumcised before it was passed. This effect would be consistent with the finding that denial rates are much higher among younger women.

Subsets of women and girls in the district have been exposed to a variety of anticircumcision campaigns and interventions that may have affected local attitudes toward female genital cutting as well as circumcised women's willingness to reveal their status to interviewers. In 1999, the Navrongo Health Research Centre began an experimental intervention program to discourage the practice. Other organizations have campaigned against female circumcision in the district as well, although the impact of these activities is unknown. Given the anticircumcision messages circulating in the district, women are likely to assume that the NHRC opposes the practice. For this reason, a woman may tell an NHRC interviewer what she thinks the interviewer wants to hear, denying that she is circumcised.

Whatever the reasons behind their responses, deniers, as compared with confirmers, are more likely to be educated and less likely to practice traditional religion, whereas they are less likely to be educated and more likely to practice traditional religion than are women who have never reported being circumcised. Women who are educated and who do not practice traditional religion may belong to an innovative group that is less likely to practice circumcision than others and that is also more sensitive to concerns leading to relatively high rates of denial.

The practice of female genital cutting is neither homogenous nor static within the district. Among residents of Navrongo town, cutting is rare. In areas where the practice continues, its prevalence is dramatically lower among younger women (as shown above 
in Table 1). The decreasing trend in prevalence may reflect a decline in the social importance and acceptability of the practice. When female circumcision was nearly universal, the social cost of not being circumcised was high for women who avoided the procedure, and uncircumcised women were subject to mocking and humiliation (Akweongo et al. 2001). Recent qualitative data suggest that this situation has been reversed, and that young women who are circumcised are likely to face ridicule from their uncircumcised peers (Akweongo 2002).

For these reasons, we hypothesize that the attitudes toward female genital cutting in the district influence girls and women to conceal the fact of having been circumcised rather than falsely report it. In support of this hypothesis, denial rates are highest among groups of women with the lowest prevalence of circumcision; presumably social pressure to remain uncircumcised would be greatest among groups with low prevalence.

The converse relationship between denial and prevalence raises the following question, however: Is the low reported prevalence of female genital cutting merely a function of high denial rates, or are denial rates high because the increasingly low prevalence of the practice among peers is associated with social pressure to remain uncircumcised? The truth likely lies somewhere in between. Denying that one is circumcised becomes increasingly desirable as the social acceptability of the practice declines. Although denial is likely to contribute to decreases in self-reported prevalence, denial is unlikely to be the sole reason for these decreases.

Denial or inconsistent reporting of circumcised status may also be attributable to inappropriate data-collection procedures. Repetitive questioning about their circumcision status may confuse women who had already reported being circumcised to NHRC staff in a previous survey, and repeated interviewing may be associated with higher rates of denial than are single-observation surveys. Unskillful or inappropriate interviewers may cause women to feel uncomfortable about divulging such information. As circumcision becomes an increasingly sensitive topic, research procedures must be adjusted in response.

Unlike respondents in other studies that compare self-reports to the results of clinical exams, the girls and women interviewed in Navrongo had no reason to believe that the accuracy of their responses would ever be corroborated or invalidated by means of such an examination. 


\section{CONCLUSION}

This study of women's denial of having experienced female genital cutting occurred in a setting where social support for the practice is eroding, interventions are taking place, laws against the practice are being enforced, and informational campaigns have been launched. Denial of being circumcised in women's self-reports may spuriously inflate estimates of the impact of interventions. Results of this analysis attest to the need for greater attention to methodological problems in research on female genital cutting.

The number of women who deny that they have been circumcised is likely to differ widely by survey setting. Questions must be raised about the validity of selfreported data, particularly in situations where interventions or laws to halt circumcision are in place or where the social acceptability of the practice is decreasing. When the goal of an intervention is to stop the practice, the intervention may simply change women's responses to survey questions about their circumcision status. Anticircumcision laws are also likely to change the reliability of self-reported data. Although no generic solution exists for this problem, caution is necessary when results are interpreted, because research aimed at evaluating means of preventing the practice will be compromised if social-mobilization interventions affect the propensity for denial as much as or more than they affect the practice itself. Data-collection strategies tailored to individual communities are crucial for conducting research on this sensitive topic. Where longitudinal data are available, parameters for models explaining denial can be used to adjust incidence data for hazard models. Longitudinal incidence data are thus less likely to be biased by denial than are cross-sectional prevalence data. Results from this study suggest that greater caution should be directed to the interpretation of cross-sectional data, because denial rates and their determinants in such studies are unknown.

\section{NOTES}

1 National prevalence of female genital cutting was assessed between 1989 and 1999 in the Demographic and Health Surveys for Burkina Faso, Central African Republic, Côte d'Ivoire, Egypt, Eritrea, Guinea, Kenya, Mali, Niger, Nigeria, northern Sudan, and Tanzania (Yoder and Mahy 2001). 
2 The majority of countries in Africa where female genital cutting takes place have enacted laws against the practice or published policies against it. Such laws or policies exist in Benin, Burkina Faso, Cameroon, Central African Republic, Chad, Côte d'Ivoire, Djibouti, Egypt, Eritrea, Ethiopia, Gambia, Ghana, Guinea, Kenya, Liberia, Mali, Nigeria, Senegal, Sierra Leone, Somalia, northern Sudan, Tanzania, Togo, and Uganda, but not in the Democratic Republic of the Congo, GuineaBissau, Mauritania, or Niger (see Toubia 1993 and 1996; WHO 1999; United States Department of State 2001). See Population Council (2002) for further discussion of the difficulty in measuring indicators of female genital cutting.

3 A rare example is a 1999 study conducted in rural Gambia of women aged 15-49 (Morison et al. 2001).

$4 \quad$ Huntington and his colleagues do not give a breakdown of raw numbers. These proportions were estimated from percentages and numbers reported by Huntington et al. (1996) and are subject to bias from rounding. Medical examination and self-reports agreed that 92 percent of the 1,339 women in the study-approximately 1,232 women - had undergone genital cutting. Self-reports and exams agreed that 2 percent—approximately 27 women—had not been circumcised. One percent of the sample of 1,339 women-about 13 women-whose examinations classified them as circumcised reported that they were not. Alternatively, 5 percent—about 67 women—reported that they had been circumcised, whereas gynecological examinations determined that they had not. Thus, about 67 of the approximately 94 women assessed as uncircumcised in their gynecological exam reported that they had been circumcised ( 71 percent), and about 1 percent (13 out of 1,245 ) of the women who were assessed by examination as circumcised reported that they were not.

5 These figures were calculated using denominators approximated from data presented in Morison et al. (2001). Morison and her colleagues report that 668 of 1,157 women who were examined by a gynecologist showed signs of genital cutting and that 1,156 women who were examined also reported their circumcision status. Thus, of these 1,156 women, 667 or 668 were classified as circum- 
cised and 488 or 489 were classified as not circumcised. Morison and her colleagues note that 21 women who reported being circumcised showed no signs of the operation and two women who reported being "sealed" were found not to be. Thus, a total of 23 women (4.7 percent) of the 488 or 489 women found to be uncircumcised in their exam reported some type of genital surgery. Seven women (1 percent) of the 667 or 668 who were classified as circumcised in their exam reported that they were not circumcised. Among these 667 or 668 women who were found to have experienced genital surgeries during their exam, ten (1.5 percent) misreported the type of circumcision they had undergone.

6 These numbers are based on Larsen and Okonofua's (2002) report of 94 percent sensitivity and 91 percent specificity of self-reported survey responses in identifying individuals' circumcision status as determined by subsequent gynecological exam. They also found that women had a poor knowledge of the type of cutting they had experienced; 76 percent of women found to be circumcised in an exam did not know what type of procedure they had undergone or did not answer the question.

7 Snow et al. (2002) concluded that women who were not circumcised were less sure of their status, based on their finding that most of the women who did not know whether they were circumcised in fact were not. They also found that invalid answers were more frequent among groups of women with a lower prevalence of cutting.

8 The results of the 1995 survey are described in detail in Mbacké et al. (1998). Because of high rates of migration both within and outside the study district, and because only women aged 15 to 44 in 1995 fell into the 15-to-49 age category eligible for interview five years later, fewer than half of women interviewed in 1995 were reinterviewed in 2000 . Only 52 percent $(2,401$ of the 4,637 women aged 15 to 44 in the 1995 panel) of eligible women were reinterviewed in 2000. Therefore, results must be interpreted with caution. Women lost to follow-up would not have been likely to change their self-reported circumcision status at a different rate than would women not lost to follow-up. Women interviewed for 
the first time in 2000, after a local circumcision practitioner was jailed and awareness grew of the law against female genital cutting, might have been more likely, however, to deny that they are circumcised than were women interviewed in both years. Clearly, circumcised women interviewed for the first time in $2000 \mathrm{had}$ never reported to survey interviewers that they were uncircumcised, whereas women interviewed in both years who reported that they were circumcised in 1995 might hesitate to give a contradictory report in 2000 .

9 Anecdotal evidence suggests that this finding may be the result of public awareness caused by the arrest of a male Nankam circumciser who was convicted for breaking the national law against genital cutting in 1996. Subsequently, he served a five-year prison term.

10 If we excluded deniers, prevalence would be 86 percent.

11 Although the mean age of female genital cutting is 15.5 years (Mbacké et al. 1998), older women do, apparently, undergo circumcision. Mbacké et al. write, "In the Kassena-Nankana District, FGM is a precursor to marriage. Even if a woman is not circumcised before her marriage, she is very likely to be so immediately after marriage." Fifty-four percent of never-married women aged 25 years and older are circumcised, compared with 91 percent of ever-married women aged 25 years and older.

\section{REFERENCES}

Adongo, Phillip, Patricia Akweongo, Fred Binka, and Cheikh Mbacké. 1998. "Female genital mutilation: Sociocultural factors that influence the practice in KassenaNankana District, Ghana." African Journal of Reproductive Health 2(2): 25-36.

Akweongo, Patricia. 2002. Research Officer at the Navrongo Health Research Centre and Principal Investigator of the Navrongo FGM Intervention. Personal communication.

Akweongo, Patricia, Shirley Appiah-Yeboah, Evelyn Sakeah, Elizabeth F. Jackson, and James F. Phillips. 2001. “The women's thing: Gender roles sustaining the practice of female genital mutilation in northern Ghana." Paper presented at the 2001 annual meetings of the Population Association of America, Washington, DC, 29-31 March. 
El-Gibaly, Omaima, Barbara Ibrahim, Barbara Mensch, and Wesley Clark. 2002. "The decline of female circumcision in Egypt: Evidence and interpretation." Social Science and Medicine 54: 205-220.

Huntington, Dale et al. 1996. Clinic-based Investigation of the Typology and Self-reporting of FGM in Egypt. Report. Cairo and Calverton, MD: Population Council, Egyptian Fertility Care Society, and Macro International.

Jones, Heidi, Nafissatou Diop, Ian Askew, and Inoussa Kaboré. 1999. "Female genital cutting practices in Burkina Faso and Mali and their negative health outcomes." Studies in Family Planning 30(3): 219-230.

Larsen, Ulla and Friday E. Okonofua. 2002. "Female circumcision and obstetric complications." International Journal of Gynecology \& Obstetrics 77(2): 255-326.

Mbacké, Cheikh, Phillip Adongo, Patricia Akweongo, and Fred N. Binka. 1998. "Prevalence and correlates of female genital mutilation in the Kassena-Nankana District of Northern Ghana." African Journal of Reproductive Health 2(2): 13-24.

Mensch, Barbara S., Daniel Bagah, Wesley H. Clark, and Fred Binka. 1998. "The Changing Social Environment for Adolescents in Kassena-Nankana District of Northern Ghana: Implications for Reproductive Behavior." Policy Research Division Working Paper No. 110. New York: Population Council.

Morison, Linda et al. 2001. "The long-term health consequences of female genital cutting in rural Gambia: A community-based survey." Tropical Medicine and International Health 6(8): 643-653.

Obermeyer, Carla Makhlouf. 1999. "Female genital surgeries: The known, the unknown, and the unknowable." Medical Anthropology Quarterly 13(1): 79-106.

Population Council. 2002. Using Operations Research to Strengthen Programmes for Encouraging the Abandonment of Female Genital Cutting. Report. Nairobi: Population Council.

Rattray, R.S. 1932. The Tribes of the Ashanti Hinterland. Oxford: Clarendon Press.

Sedgh, Gilda and Elizabeth F. Jackson. 2003. "Toward the abandonment of female genital cutting: Advancing research, communication, and collaboration." Unpublished. 
Shell-Duncan, Bettina and Ylva Hernlund. 2000. "Female 'circumcison' in Africa: Dimensions of the practice and debates." In Female "Circumcision" in Africa: Culture, Controversy, and Change. Eds. Bettina Shell-Duncan and Ylva Hernlund. Boulder, CO: Lyne Reinner. Pp. 1-40.

Snow, R.C., T.E. Slanger, Friday E. Okonofua, F. Oronsaye, and J. Wacker. 2002. "Female genital cutting in southern urban and peri-urban Nigeria: Self-reported validity, social determinants and secular decline." Tropical Medicine and International Health 7(1): 91-100.

Toubia, Nahid. 1993. Female Genital Mutilation: A Call For Global Action. New York: Population Council.

— 1996. "Two million girls a year mutilated." In The Progress of Nations 1996: Women. New York: UNICEF. P. 14.

United States Department of State (USDOS). 2001. "Female Genital Mutilation (FGM) or Female Genital Cutting (FGC): Individual Country Reports." Washington, DC: USDOS, Office of the Senior Coordinator for International Women's Issues, 1 June.

World Health Organization (WHO). 1999. "Female genital mutilation programs to date: What works and what doesn't. A review." Geneva: WHO Department of Women's Health, Health Systems and Community Health.

Yoder, P. Stanley and Mary Mahy. 2001. Female Genital Cutting in Guinea: Qualitative and Quantitative Research Strategies. DHS Analytical Studies No. 5. Calverton, MD: ORC Macro. 


\title{
POLICY RESEARCH DIVISION WORKING PAPERS
}

\author{
Recent Back Issues
}

144 John Bongaarts, "Household size and composition in the developing world."

145 John B. Casterline, Zeba A. Sathar, and Minhaj ul Haque, "Obstacles to contraceptive use in Pakistan: A study in Punjab."

146 Zachary Zimmer, Albert I. Hermalin, and Hui-Sheng Lin, "Whose education counts? The impact of grown children's education on the physical functioning of their parents in Taiwan."

147 Philomena Nyarko, Brian Pence, and Cornelius Debpuur, "Immunization status and child survival in rural Ghana."

*148 John Bongaarts and Zachary Zimmer, "Living arrangements of older adults in the developing world: An analysis of DHS household surveys."

149 Markos Ezra, "Ecological degradation, rural poverty, and migration in Ethiopia: A contextual analysis."
150 Cynthia B. Lloyd, Sahar El Tawila, Wesley H. Clark, and Barbara S. Mensch, "Determinants of educational attainment among adolescents in Egypt: Does school quality make a difference?"

151 Barbara S. Mensch, Paul C. Hewett, and Annabel Erulkar, "The reporting of sensitive behavior among adolescents: A methodological experiment in Kenya."

152 John Bongaarts, "The end of the fertility transition in the developed world."

153 Mark R. Montgomery, Gebre-Egziabher Kiros, Dominic Agyeman, John B. Casterline, Peter Aglobitse, and Paul Hewett, "Social networks and contraceptive dynamics in southern Ghana."

*154 Paul C. Hewett and Mark R. Montgomery, "Poverty and public services in developing-country cities."

* No longer available 
155 Zachary Zimmer, Linda G. Martin, and Ming-Cheng Chang, "Changes in functional limitations and survival among the elderly in Taiwan: 1993, 1996, and 1999."

156 John Bongaarts and Griffith Feeney, "How long do we live?"

157 Zachary Zimmer and Sovan Kiry Kim, "Living arrangements and socio-demographic conditions of older adults in Cambodia."

158 Geoffrey McNicoll, "Demographic factors in East Asian regional integration."

159 Carol E. Kaufman, Shelley Clark, Ntsiki Manzini, and Julian May, "How community structures of time and opportunity shape adolescent sexual behavior in South Africa."

*160 Julia Dayton and Martha Ainsworth, "The elderly and AIDS: Coping strategies and health consequences in rural Tanzania."

161 John Bongaarts, "The end of the fertility transition in the developing world."
162 Naomi Rutenberg, Carol E. Kaufman, Kate Macintyre, Lisanne Brown, and Ali Karim, "Pregnant or positive: Adolescent childbearing and HIV risk in South Africa."

163 Barbara S. Mensch, Wesley H. Clark, and Dang Nguyen Anh, "Premarital sex in Vietnam: Is the current concern with adolescent reproductive health warranted?"

164 Cynthia B. Lloyd, Cem Mete, and Zeba A. Sathar, "The effect of gender differences in primary school access, type, and quality on the decision to enroll in rural Pakistan."

165 Kelly Hallman, Agnes R. Quisumbing, Marie Ruel, and Bénédicte de la Brière, "Childcare, mothers' work, and earnings: Findings from the urban slums of Guatemala City."

*166 Carol E. Kaufman and Stavros E. Stavrou, “'Bus fare, please': The economics of sex and gifts among adolescents in urban South Africa."

*167 Dominic K. Agyeman and John B. Casterline, "Social organization and reproductive behavior in southern Ghana." 
168 Paul C. Hewett, Annabel S. Erulkar, and Barbara S. Mensch, "The feasibility of computer-assisted survey interviewing in Africa: Experience from two rural districts in Kenya."

169 Zachary Zimmer and Julia Dayton, "The living arrangements of older adults in sub-Saharan Africa in a time of HIV/AIDS."

170 Ravai Marindo, Steve Pearson, and John B. Casterline, "Condom use and abstinence among unmarried young people in Zimbabwe: Which strategy, whose agenda?"

171 Sajeda Amin and Nagah H. AlBassusi, "Wage work and marriage: Perspectives of Egyptian working women."

172 Zachary Zimmer, Napaporn Chayovan, Hui-Sheng Lin, and Josefina Natividad, "How indicators of socioeconomic status relate to physical functioning of older adults in three Asian societies."

173 Paul Demeny, "Population policy: A concise summary."
174 Geoffrey McNicoll, "Population and development: An introductory view."

175 James F. Phillips, Tanya C. Jones, Frank K. Nyonator, and Shruti Ravikumar, "Evidence-based development of health and family planning programs in Bangladesh and Ghana."

176 Cynthia B. Lloyd and Paul C. Hewett, "Primary schooling in sub-Saharan Africa: Recent trends and current challenges."

177 John Bongaarts, "Completing the fertility transition in the developing world: The role of educational differences and fertility preferences."

178 Elizabeth F. Jackson, Patricia Akweongo, Evelyn Sakeah, Abraham Hodgson, Rofina Asuru, and James F. Phillips, "Women's denial of having experienced female genital cutting in northern Ghana: Explanatory factors and consequences for analysis of survey data." 
